\title{
Génesis de la publicidad técnica en España. El caso de El Bazar Murciano (1892-1929)
}

\author{
Genesis of technical advertising in Spain. The case of El Bazar \\ Murciano (1892-1929)
}

\section{Gênese da publicidade técnica na Espanha. O caso do El Bazar Murciano (1892-1929)}

María Arroyo Cabello, Universidad Católica de Murcia, Murcia, España (msarroyo@ucam.edu)

\begin{abstract}
RESUMEN | La publicidad técnica comienza a gestarse en España en el primer tercio del siglo XX, impulsada por Pedro Prat Gaballí, seguidor de la publicidad científica que Claude Hopkins desarrollaba en Estados Unidos. En ese contexto, este artículo aborda la actividad publicitaria de un comerciante que a finales del siglo XIX y principios del XX lleva a cabo estrategias publicitarias modernas, todavía innominadas. El descubrimiento de contenido de marca en El Bazar Murciano, órgano de prensa (house organ) del comercio del mismo nombre, plantea el estudio desde la inédita perspectiva publicitaria en el contexto económico, social y cultural del momento. La metodología utilizada en este trabajo consiste en la revisión hemerográfica del periódico anual El Bazar Murciano desde su fundación en 1892 hasta su cese en 1929. En total son 38 ejemplares, que se encuentran digitalizados en el Archivo Municipal de Murcia. Para la muestra se han seleccionado seis textos representativos del elenco de colaboraciones, a los que se les ha aplicado un análisis de contenido para evidenciar que se trata de un órgano de prensa que responde a la estrategia publicitaria de información de marca. Los resultados revelan que el fundador de El Bazar Murciano creó uno de los primeros house organs que se editaron en España, un periódico pionero en aplicar el contenido de marca optimizando el auge del periodismo literario, costumbrista y humorístico del primer tercio del siglo XX.
\end{abstract}

PALABRAS CLAVE: El Bazar Murciano; house organ; contenido de marca; historia; publicidad; España; siglo XIX; siglo XX. 
ABSTRACT / Technical advertising began to take shape in Spain in the first third of the 20th century, promoted by Pedro Prat Gaballi, follower of the scientific advertising that Claude Hopkins developed in the United States. In that context, this article deals with the advertising activity of a merchant who, in the late 19th and early 20 th centuries, developed modern advertising strategies, still unnamed. The discovery of branded content in $\mathrm{El}$ Bazar Murciano, a house organ of the trade of the same name, proposes the study from an unprecedented advertising perspective in the economic, social and cultural context of the moment. The methodology used starts from the newspaper review of El Bazar Murciano from its foundation in 1892 to its cessation in 1929. In total there are 38 copies, digitized in the Municipal Archive of Murcia. We have selected six representative texts from the cast of collaborations for the sample, to which we applied a content analysis to show that it is a house organ that responds to the branded content advertising strategy. The results reveal that the founder of El Bazar Murciano created one of the first house organs published in Spain, a pioneering newspaper in applying branded content optimizing the rise of literary, customary and humorous journalism in the first third of the 20th century.

KEYWORDS: El Bazar Murciano; house organ; branded content; history; advertising; Spain; 19th century; 20th century.

RESUMO | A publicidade técnica começa a ser gestada na Espanha na primeira metade do século XX fomentada por Pedro Prat Gaballí, adepto da publicidade científica que Claude Hopkins desenvolvia nos Estados Unidos. Este artigo aborda a atividade publicitária de um comerciante, que para finais do século XIX e início do século XX, desenvolveu estratégias publicitárias modernas, ainda inominadas. O descobrimento de conteúdo de marca no El Bazar Murciano, órgão de imprensa (house organ) do comércio do mesmo nome, planteia o estudo desde a inédita perspectiva publicitária no contexto econômico, social e cultural do momento. A metodologia utilizada parte da revisão hemerográfica do El Bazar Murciano, desde sua fundação em 1892 até seu fechamento em 1929. No total são 38 exemplares que se encontram digitalizados no Arquivo Municipal de Murcia. Para a mostra foram selecionados seis textos representativos do conjunto de colaborações, aos quais se aplicaram uma análise de conteúdo para evidenciar que se trata de um órgão de imprensa que responde à estratégia publicitária de informação de marca. Os resultados revelam que o fundador do El Bazar Murciano criou um dos primeiros house organs que foram editados na Espanha, um periódico pioneiro na aplicação do conteúdo de marca otimizando o auge do jornalismo literário, de costumes e humorístico da primeira metade do século XX.

PALAVRAS-CHAVE: El Bazar Murciano; house organ; conteúdo de marca; história; publicidade; Espanha; século XIX; século XX. 


\section{INTRODUCCIÓN}

La publicidad técnica comienza a gestarse en España en el primer tercio del siglo XX, impulsada por Pedro Prat Gaballí (1885-1962), seguidor de las investigaciones científicas de la publicidad que Claude Hopkins (1867-1932) estaba desarrollando en Estados Unidos. Quintas Froufe (2011) ha mostrado cómo Prat Gaballí aspiraba a equiparar la publicidad española a la estadounidense mediante la difusión de su ingente legado: sus libros Publicidad científica (1917), Publicidad racional (1934), y Publicidad combativa (1957), entre otras contribuciones, lo erigen en un referente esencial de la historia de la publicidad española.

Por otra parte, a Prat Gaballí le cabe el mérito de infundir estabilidad y profesionalidad a la publicidad española y, como recuerda Eguizábal Maza (1998, p. 453), la primera revista donde se abordan temas publicitarios es obra suya; igualmente, su libro Publicidad científica (1917) es pionero en esta materia en todo el mundo, pues la obra de Claude Hopkins Scientific advertising (1923) apareció seis años después.

Prat Gaballí (1934) se refería a la agencia Fama cuando señala el año 1919 como el del nacimiento en España de "la agencia técnico-mixta que, además de actuar de intermediario entre el anunciante y el periódico, ofrece un servicio técnico real" (p. 250). La agencia técnica no se limitaba a una función mediadora entre los anunciantes y la prensa, sino que proporcionaba asesoramiento y servicio al cliente a través de los siguientes departamentos: a) Análisis de mercado, investigación y estadística, b) Estudio y creación de marcas y presentaciones, c) Ideas, preparación técnica de campañas y redacción, d) Publicidad directa y e) Administración (presupuestos, tarifas) (Prat Gaballí, 1934).

Por consiguiente, el proceso de tecnificación de la publicidad española se debe a Prat Gaballí, considerado el padre de la publicidad moderna y el mejor representante en dicho país de la llamada publicidad científica. Sus hallazgos en la psicología experimental aplicada a la industria publicitaria y su defensa de la "ventaja específica" determinan su actividad como publicista (Checa Godoy, 2007, p. 105).

Pero también es justo mencionar a los empresarios del sector de la perfumería, que transformaron la fabricación de productos en industria de marca; entre ellos figura Echeandía, fundador de Gal y "precursor de la aplicación de las técnicas publicitarias modernas de Prat Gaballí" (Apuntes sobre la publicidad..., 1950). El mismo Prat (1934, pp. 7-8) reconoce el mérito del dueño de Gal, quien en 1919 creó un departamento técnico de publicidad hasta entonces inexistente en España. Sin embargo, no fue el único: otros empresarios del sector como Alejandro Berenguer y Pascual Flaubel, propietarios de perfumería Floralia, Esteve Monegal y Prat de 
Mirurgia, y Joan Parera, de perfumería Parera, hicieron lo propio en los primeros decenios del siglo pasado.

Ahora bien, no solo destacó el sector de la perfumería, sino que también los propietarios de grandes almacenes, como El Siglo desde 1883 en Barcelona o El Bazar Murciano desde 1892, emplearon estrategias publicitarias actuales todavía innominadas como órganos de prensa (house organs) y contenido de marca. Se entiende por información de marca o branded content el:

Contenido producido, coproducido o auspiciado por la marca que, sin ser publicidad, transmite sus valores y posicionamiento entreteniendo, educando o formando al público al que va dirigido. La clave es que sea un contenido relevante y de interés. Que aporte valor, que conecte y que fomente la participación de los públicos generando comunidad en torno a la marca. No es, por tanto, un contenido publicitario, sino un contenido de valor que tiene detrás a una marca cuya esencia la legitima para proporcionar ese contenido. No es un marketing intrusivo, sino un contenido que es consumido libremente y proactivamente por la audiencia (Asociación de Empresas Consultoras en Relaciones Públicas y Comunicación, 2018, p. 7).

Por cierto, uno de los primeros casos de contenido de marca que se conocen es un libro de recetas de la marca Royal de 1888 (Rudmani, 1888). Así pues, la publicidad española no andaba muy lejos de la de los países occidentales. Julián Bravo (1978) equipara la actividad publicitaria de los anunciantes españoles a la que se estaba desarrollando en Estados Unidos y Europa.

Son varios los autores que coinciden en subrayar el rol de las empresas en la tecnificación de la publicidad. Pérez Ruiz (2001) señala que fue la iniciativa privada de los anunciantes la que puso en marcha "un cierto ejercicio ordenado de la publicidad" (p. 94). Y Bravo (1978) advierte que no fueron las agencias, sino las empresas anunciantes y los propietarios quienes se preocuparon por conocer y desarrollar la nueva técnica publicitaria. Jesús Reina (2015) asegura que

Los primeros house organ que se editaron en España no fueron pensados ni diseñados por profesionales de la comunicación, sino por la propia dirección de la empresa, como consecuencia de unas necesidades comunicativas a cubrir, principalmente de contacto y promoción de los públicos (p. 101).

Uno de estos órganos es el periódico anual El Bazar Murciano, al servicio de unos grandes almacenes de Murcia, que por su calidad literaria constituye un hito en la historia del periodismo local. 
El Bazar Murciano ha sido estudiado desde el ámbito del periodismo y la literatura (Ballester, 1971; Barceló Jiménez, 1980; Crespo, 1984, 2000; Díez de Revenga \& De Paco, 1989; Moreno Requena, 2007; Ayuso \& García, 2011), entre otros, sin duda por su potente contenido poético y narrativo unido al prestigio de sus firmas, pero obviando, sin embargo, su dimensión comunicativa publicitaria. Sin embargo, El Bazar Murciano pertenece a las revistas corporativas, instrumentos que utilizan las empresas para presentarse ante sus públicos de interés como actor social, más rentables que como sujeto meramente económico (Capriotti, 2007). En este sentido, el fundador de El Bazar Murciano fue uno de los primeros que confiaron en la publicidad, creando un órgano de prensa que, además, usa la estrategia de contenido de marca para proporcionar reputación al comercio y fidelizar a los usuarios con contenidos literarios realizados por relevantes escritores de la época, optimizando el auge del periodismo-literario, costumbrista y humorístico del primer tercio del siglo XX.

\section{MARCO TEÓRICO}

\section{La modernización de España}

A principios del pasado siglo España entra en la modernidad con una prometedora transformación económica y social, que para García Delgado (2002, p. 55) se consolidará a lo largo del reinado de Alfonso XIII y situará el país a la altura de su tiempo. El crecimiento del tejido productivo y la renovación tecnológica en el campo y en la industria, el regreso del capital procedente de las colonias de ultramar y la llegada de inversores europeos, más los beneficios que reporta la neutralidad en la Primera Guerra Mundial, son algunos de los factores que contribuyen al desarrollo económico del país.

La activación de la economía propicia el nacimiento de una clase social urbana procedente de sectores industriales o profesionales, con capacidad adquisitiva suficiente para comprar bienes de consumo reservados hasta entonces a una extracción social alta. La publicidad no podía permanecer ajena a este fenómeno, que le abría un campo de acción más amplio, y se dirigió a la conquista de su nuevo público de "ricos y pobres" (Montero, 2011, p. 353).

El resultado es la aparición en el periodo de entreguerras de un modelo de consumo emergente que dará lugar a la primera sociedad de masas, si bien no se consolidará en España hasta los años sesenta (Alonso \& Conde, 1994). Se trata de una forma de consumo fordista, que cohabita durante los primeros decenios del siglo $\mathrm{XX}$ con el prefordista y exclusivo, ya establecido. Ambos modelos responden a un estilo de publicidad diferente: mientras este último asocia los productos a elegancia y distinción, valores adscritos a la aristocracia y a los terratenientes, el primero 
los vincula, en cambio, a modernidad, comodidad y practicidad, características de la burguesía urbana. Poco a poco este tipo de consumo va imponiéndose en las ciudades, donde proliferan comercios y bazares, que, según Arribas Macho (1994) facilitan la compra mediante el crédito y la venta a plazos, lo que permite a la clase trabajadora adquirir bienes de consumo, algo impensable dos decenios antes ${ }^{1}$.

Simultáneamente, se experimenta un crecimiento demográfico, el proceso de urbanización de las ciudades y el emprendimiento de reformas educativas, que mejoran los sueldos de los maestros, reducen las tasas de analfabetismo; asimismo, se adoptan medidas de apoyo a la investigación científica, circunstancias - todas ellas- que influyen en los cambios sociales posteriores.

A su vez, se atisba un cambio cultural y de costumbres que se manifiesta en la literatura -con la generación del 14 y la del 27-, la irrupción de intelectuales de la talla de Ortega y Gasset, la apertura de universidades o la renovación de las artes plásticas, entre otras expresiones. Un despertar cultural que, como ha hecho notar Fusi (2007), "no es casual ni fruto de figuras aisladas, sino un hecho social de considerable entidad cuantitativa y cualitativa” (p. 537).

Por lo demás, España - al igual que otros países del entorno- incorpora los adelantos de la vida moderna como el gas, la electricidad, el tranvía, el automóvil, el cinematógrafo, los espectáculos, el deporte o la moda (Folguera,1987).

No obstante, esta modernización se percibe no solo en la capital, sino también en otras ciudades, por ejemplo Murcia, en donde la industria agroalimentaria y conservera se transforma, se adopta una política de construcción de embalses y se produce el incremento de las exportaciones agraria y minera y la entrada de capital foráneo, argumentos que dinamizan la economía regional (Rodríguez Llopis, 1998). Asimismo, se emprende la apertura de sucursales de los grandes bancos y la necesaria reforma urbanística de la ciudad (Rodriguez Llopis, 1998).

A la prosperidad económica se suma el aumento de la población, que, como ha sabido advertir Rodríguez Llopis (1998), constituye uno de los logros más significativos de la región durante los tres primeros decenios del siglo XX. Al propio tiempo es una etapa de crecimiento cultural asociado a la creación en 1915 de la Universidad de Murcia, el auge en los años 20 y 30 de revistas literarias y la presencia en Murcia del poeta Jorge Guillén, en torno al cual se forma un grupo de intelectuales "que elevaron la literatura a interesantes cotas de modernidad" (Díez de Revenga \& De Paco, 1989, p. 316).

1. Para profundizar en las causas sociales, económicas y culturales que favorecieron la sociedad de consumo, véase Eguizábal, 2006. 
Además, el periodismo murciano evoluciona dejando atrás al periódico artesanal - con el cese de cinco diarios nacidos en el siglo XIX - y encaminándose hacia al periodismo empresarial que representa El Liberal de Murcia, perteneciente a una cadena periodística con implantación en otras ciudades, y hacia el nacimiento de nuevas cabeceras: El Liberal de Murcia en 1902, La Verdad en 1903 y El Tiempo en 1908 (Arroyo Cabello, 1997).

De este modo, Murcia se asoma a la modernidad con la implementación de un nuevo estilo de vida, sobre todo en los años 20 , que se refleja en la vanguardia artística (pintura, escultura y dibujo), las revistas gráficas y deportivas, las tertulias, los cafés y el cine (Arroyo Cabello, 1994), sin perder por ello su carácter tradicional.

En consecuencia, la transformación paulatina del país en este periodo abre un panorama inédito a la publicidad española: la gama de productos se amplía notablemente, los comerciantes se convierten en anunciantes, algunas marcas cuentan con un departamento de publicidad, incluso con una agencia cautiva (Veritas creada por Gal en 1927 es la primera agencia española dependiente de un anunciante), las agencias inician funciones técnicas en la elaboración de anuncios (Fernández Poyatos, 2010) y se otorga una base científica a la profesión con el magisterio de Pedro Prat Gaballí.

\section{El comercio El Bazar Murciano, una institución en Murcia}

A mediados del siglo XIX surge en las ciudades una nueva forma de venta: los almacenes y bazares, que se distinguen de las tiendas porque ofrecen todo tipo de mercancías en un mismo establecimiento, precios asequibles y un horario flexible. En los grandes almacenes coincidían las clases populares y la burguesía practicando idéntica forma de consumo. Faciabén (2003) observa que "estos comercios no estaban dirigidos únicamente a cubrir las necesidades de las clases medias y alta, sino que pretendían llegar a toda la población" (p. 2).

Uno de los primeros almacenes que se inauguraron en Barcelona en 1878 fue El Siglo, situado en la céntrica Rambla de los Estudiantes 5 y en Xuclé, 10 y 12, que contaba con doscientos cincuenta empleados y que es un exponente del potencial mercantil catalán. Pero había más, como recoge la prensa de entonces: entre 1880 y 1915 se instalan en las ciudades españolas los grandes almacenes El Principal, Old England, La Tropical, El Día, El Barato, El Globo o El Águila.

En 1897, El Diario de Murcia citaba varios almacenes en el centro de la ciudad, a saber, Los Muchachos ubicado en las Cuatro esquinas, en la confluencia de las calles Platería y Trapería, Las Maravillas en el número 88 de Platería o El Gran Barato de la Villa de Paris en la calle Trapería. 
El periodista José Martínez Tornel define la calle Platería como la arteria principal de la ciudad, la más céntrica, la de mayor movimiento, en la que más se renuevan los establecimientos y se manifiesta su cosmopolitismo mercantil (1906, p. 1)2.

El 10 de marzo de 1890, en su tercera página, El Diario de Murcia informaba de la novedad que representaba para la ciudad la apertura de un comercio dedicado a la venta de quincalla, bisutería, perfumería y paquetería, que abría a las 6:30 de la mañana y cerraba a las 23:45 de la noche o después, mientras hubiera clientes.

El propietario, Ricardo Blázquez, oriundo de La Rioja, fue quien — con ayuda de un tío- abrió en el mejor sitio de la ciudad, en la calle Platería 66 y 68 esquina a la plaza de Joufré, un bazar de dos plantas con dos entradas, una por Platería y otra por la plaza Joufré. Dos rótulos hacían referencia al comercio y a su propietario: uno en el primer piso con el letrero El Bazar Murciano e iconografía de los artículos expuestos y otro en la planta baja, encima de la puerta de entrada y de igual tamaño, dedicado a Ricardo Blázquez. Al parecer, ambos, dueño y comercio, constituían por igual la imagen de marca del negocio.

El Bazar Murciano era una especie de Arca de Noé, donde se vendía de todo, desde regalos, objetos de escritorio, abanicos, paraguas, bastones, lámparas, quinqués, jarrones, hasta armas damasquinadas, soldaditos de ploma, textil, bisutería hasta vinos y charcutería; pero lo que entre todos descollaba eran los artículos de perfumería, los juguetes y los preciados cubiertos de plata Meneses exclusivos del bazar, grabados con el nombre de la marca. Estas piezas, que se vendían a 2 pesetas, eran solicitadas de todas partes.

El comercio tuvo tal afluencia de público que en 1902 el señor Blázquez abriría una sucursal en el número 33 de la calle Mayor de Cartagena, muy parecido al de Platería en Murcia (Ferrández García, 2017). La inauguración fue un acontecimiento social al que acudieron las personas más distinguidas de la ciudad departamental, según la crónica de Valcárcel (1902, p. 4).

Enseguida el Bazar Murciano se haría famoso, primero, porque ningunos almacenes semejantes podían competir con él en variedad, calidad, novedad y precio. Ricardo Blázquez era una persona proactiva que viajaba frecuentemente a París, Berlín o Londres para traer a Murcia las novedades del mercado, y visitaba Madrid con regularidad para ver los últimos catálogos que las marcas mostraban a los comerciantes de la capital. En segundo lugar, ganaría fama porque el antiguo dependiente del Bazar de la Puxmarina estaba dotado de cualidades innatas para

2. La calle Platería debe su nombre al gremio de plateros y joyeros, que escogieron este lugar para establecerse durante la ocupación árabe; otras calles con nombre gremial son Trapería (telas), Jabonerías (jabones) y Frenería (frenos para carruajes). 
vender: por ejemplo, se adelantaba a las necesidades de los consumidores, y al inicio de curso avisaba de que disponía de material escolar (plumas, papel, lapiceros, tinta); en vísperas del Día de Difuntos, anunciaba en la prensa su colección de coronas fúnebres (Rubio Román, 2012, p. 6).

A esta disposición para la venta se sumaba su carácter discreto, jovial, buen conversador y el trato amable y respetuoso que dispensaba a los clientes. De la misma manera, contaba con la ventaja de que se relacionaba con todo género de público, desde personas de clase media y acomodada a clases populares, intelectuales, profesionales liberales, autoridades locales civiles, militares y religiosas. El director de El Diario de Murcia, Martínez Tornel, ha encontrado en estas cualidades el secreto de su magia comercial, que le dio popularidad y convirtió el Bazar Murciano en una institución en Murcia.

\section{MARCO METODOLÓGICO}

Este artículo busca poner en valor la actividad publicitaria de un comerciante que, a finales del siglo XIX y primer tercio del XX, desarrolla estrategias publicitarias modernas, todavía innominadas, en los albores de la publicidad técnica en España.

El descubrimiento de contenido de marca en El Bazar Murciano, órgano de prensa del comercio del mismo nombre, plantea la investigación desde la inédita perspectiva publicitaria - dada la falta de estudios anteriores - en el contexto económico, social y cultural del momento.

La metodología utilizada parte de la revisión hemerográfica del periódico anual El Bazar Murciano desde su fundación en 1892 hasta su desaparición en 1929. En total son 38 ejemplares, que se hallan digitalizados en el Archivo Municipal de Murcia y contienen 819 colaboraciones, de las cuales 540 están escritas en verso y 279 en prosa y en las que participaron 135 colaboradores (Crespo, 1984).

Asimismo, se ha consultado el mes de septiembre, desde 1890 a 1903, de El Diario de Murcia y, de 1902 a 1929, de El Liberal de Murcia, diarios contemporáneos del periódico objeto de estudio por las referencias que pudieran hacerse al periódico analizado.

Los objetivos de este artículo son dos: por una parte, evidenciar que El Bazar Murciano es órgano de empresa y, por otra, mostrar que responde a la estrategia publicitaria del contenido de marca. Pues bien, como en este punto todas las colaboraciones son similares y los resultados del estudio son extrapolables al conjunto, hemos considerado suficiente seleccionar para la muestra seis textos: dos en verso y cuatro en prosa de autores de ámbito regional y nacional, distintivos del elenco de colaboraciones. Los textos seleccionados son los que muestra la tabla 1. 


\begin{tabular}{|c|c|c|c|c|c|}
\hline Autor & $\begin{array}{l}\text { Título del } \\
\text { artículo }\end{array}$ & Año & $\begin{array}{c}\text { Número } \\
\text { en que } \\
\text { aparece }\end{array}$ & Página & $\begin{array}{l}\text { Breve } \\
\text { biografía del } \\
\text { autor }\end{array}$ \\
\hline $\begin{array}{l}\text { Pedro Jara } \\
\text { Carrillo }\end{array}$ & Septiembre & 1906 & 18 & 4 & $\begin{array}{c}\text { (1876-1927). Poeta, periodista y } \\
\text { director de El Liberal de Murcia } \\
\text { entre } 1911 \text { y 1927. Posee una extensa } \\
\text { producción poética recogida en siete } \\
\text { libros. Escribió catorce relatos breves } \\
\text { y tres novelas. Ganó numerosos } \\
\text { concursos poéticos en los Juegos } \\
\text { Florales de Murcia y otras ciudades } \\
\text { próximas. }\end{array}$ \\
\hline
\end{tabular}

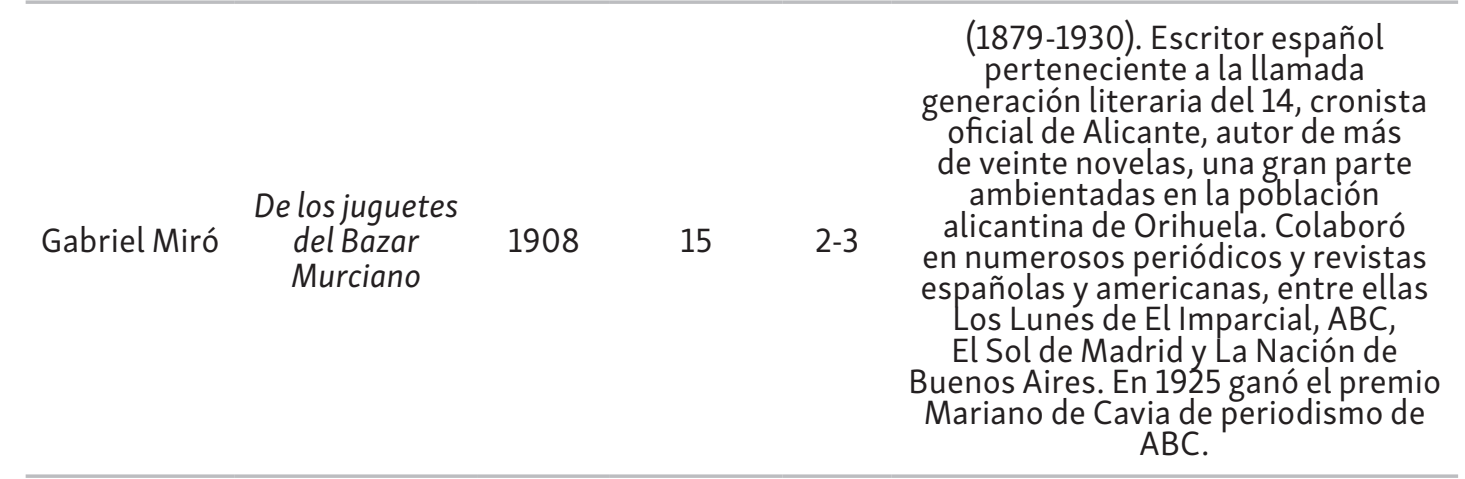

(1845-1916). Periodista, escritor, poeta, historiador, fundador y director de El Diario de Murcia, archivero del Archivo Municipal de Murcia, presidente de la Asociación

\begin{tabular}{|c|c|c|c|}
\hline $\begin{array}{c}\text { José Martínez } \\
\text { Tornel }\end{array}$ & Preámbulo & 1907 & 14 \\
\hline
\end{tabular}
de la Prensa y cronista oficial de la ciudad. Su numerosa producción literaria, histórica y antropológica sobre las tradiciones y costumbres de su tierra, por las que recibió premios y homenajes, le convierten en una personalidad relevante de la sociedad murciana entre dos siglos.

(1890-1974). Poeta y periodista, director de Levante Agrario,

\begin{tabular}{|c|c|c|c|c|c|}
\hline $\begin{array}{l}\text { Andrés } \\
\text { Bolarín }\end{array}$ & A mí, una muñeca & 1916 & 23 & 3 & $\begin{array}{l}\text { colaborador asiduo de ABC, cronista } \\
\text { oficial de Murcia y Premio Nacional } \\
\text { de Periodismo en } 1935 \text {. Autor de } \\
\text { varios libros de poemas, obtuvo } 48 \\
\text { rremios literarios }\end{array}$ \\
\hline
\end{tabular}

\begin{tabular}{|c|c|c|c|c|c|}
\hline $\begin{array}{l}\text { José Ortega } \\
\text { Munilla }\end{array}$ & $\begin{array}{l}\text { El bazares } \\
\text { un periódico }\end{array}$ & 1921 & 28 & 1 & $\begin{array}{l}\text { (1856-1922). Escritor, periodista, } \\
\text { director de El Imparcial, miembro de } \\
\text { la Real Academia Española y padre de } \\
\text { José Ortega y Gasset. Como novelista } \\
\text { cultivó el realismo literario. }\end{array}$ \\
\hline $\begin{array}{l}\text { Ricardo } \\
\text { Sánchez } \\
\text { Madrigal }\end{array}$ & $\begin{array}{l}\text { El Bazar } \\
\text { Murciano }\end{array}$ & 1922 & 29 & 4 & $\begin{array}{c}\text { (1845-1925). Poeta, periodista y } \\
\text { director de La Verdad de Murcia. } \\
\text { Cultivó la poesía lírica, el romance } \\
\text { y el teatro. En } 1877 \text { ganó el primer } \\
\text { premio en los Juegos Forales de } \\
\text { Murcia con la obra de teatro La } \\
\text { Dolorosa de Salzillo. }\end{array}$ \\
\hline
\end{tabular}

Tabla 1. Textos seleccionados de El Bazar Murciano

Fuente: Elaboración propia. 
El procedimiento seguido en la investigación ha sido, primero, confirmar que El Bazar Murciano es órgano de prensa a partir de las definiciones de autores de la época y actuales y, segundo, mostrar que los textos seleccionados satisfacen las condiciones para ser considerados información de marca. Con este objetivo se ha recurrido, por una parte, a definiciones del término y, por otra, al análisis de contenido cualitativo de los seis textos que componen la muestra, para lo cual se han determinado tres ítems, a saber, si el producto es el centro del relato, si la narración está asociada a la marca y si el valor de la información de marca se detecta con claridad. En tercer lugar, se busca averiguar la tipología de los contenidos de acuerdo a su naturaleza, finalidad y autoría.

\section{RESULTADOS}

\section{El Bazar Murciano, periódico de empresa}

En primer lugar, si nos atenemos a las definiciones de los autores de la época, El Bazar Murciano (1892-1929) es un órgano de prensa, fundado y dirigido por Ricardo Blázquez, propietario de un gran comercio de Murcia. Prat Gaballí (1917) se refiere al house organ como otro modo de hacer publicidad escrita que, en 1917, cuando escribió La Publicidad científica, tenía ya gran predicamento en algunos países. Lo describe así:

Consiste el órgano privado de una casa en una pequeña revista que publica periódicamente, cada mes, cada trimestre o cada temporada, anunciando sus artículos en diferentes formas. Esta revista, por regla general, se remite gratuitamente a los clientes reales o posibles, y a todas las personas que lo piden, a cuyo efecto se da cuenta de su aparición en los anuncios de prensa (p. 72).

Acorde con la definición, El Bazar Murciano es una publicación anual, órgano de los almacenes del mismo nombre, cuyo primer número salió el 1 de septiembre de 1892, coincidiendo con la Feria de septiembre y se publicó ininterrumpidamente hasta 1929, excepto en los años de la muerte del hermano y de la mujer del dueño, en 1898 y 1904, respectivamente. Se distribuía gratuitamente en el punto de venta, se regalaba a los amigos y conocidos y se enviaba a los periódicos locales y nacionales para darle la máxima difusión. El 4 de septiembre de 1927 El Liberal de Murcia anunciaba la aparición de un nuevo número:

Coincidiendo con el primer día de feria ha visto la luz pública el número 35 de El Bazar Murciano, periódico anual, de sabor netamente murciano, que Ricardo Blázquez mantiene a través de los años con el mismo entusiasmo de los tiempos mozos en que se decidió a actuar en el estado de la Prensa local. Su formato es el mismo de siempre y sus firmas constituyen un brillante conjunto de la literatura regional murciana, avalada por los ilustres escritores madrileños (El Liberal de Murcia, 1927, p. 1) 
Prat Gaballí (1917) continúa diciendo que el órgano de prensa puede presentar diversos aspectos:

Unos almacenes de novedades, por ejemplo, sacarán partido de su house organ, si le dan la apariencia de una revista de modas y de curiosidades, y no será de más que intercalen algo de literatura, cuentos, historietas, poesías, etc. Dichas materias formarán parte del texto general, presentadas en forma desinteresada (p. 72).

Efectivamente, los contenidos de El Bazar Murciano eran artículos literarios y poesías presentados de forma amena, y de carácter divulgativo para interesar a sus públicos.

Por su parte, Bori y Gardó (1928) entienden por house organ:

Periódico que particularmente edita un comerciante, industrial o banquero cuya finalidad no es otra que la de hacerlo servir como medio privado y exclusivo para la propaganda de sus negocios.

En realidad, no es otra cosa que un prospecto, un folleto o un pequeño catálogo disfrazado de revista y completado, para quitarle la monotonía de un impreso corriente de propaganda, con artículos de divulgación sobre asuntos que alguna relación o cuando menos consecuencia, puedan tener con el artículo anunciado (p. 24).

Si nos fijamos, viene a ser lo mismo que expresaba Ricardo Blázquez en el editorial del primer número (ver imagen 1):

Señores: Mi propósito al publicar este periódico-prospecto, es recomendar mi casa, hacer el artículo, con la serie de artículos preciosos con que me han favorecido mis buenos amigos y parroquianos y ofrecerles a ustedes nuevamente mi establecimiento. Yo no sé escribir literariamente; no entiendo de otras letras que de las letras de cambio; pero como estoy tan obligado con el público de Murcia, por lo que me favorece y me distingue, creo de mi deber corresponder a estas atenciones, haciéndolas públicas por las presentes líneas, y teniendo en mi establecimiento del Bazar Murciano, los mejores géneros del mundo, a los precios más económicos.

Vengan ustedes, señoras y señores, a honrar mi casa en la presente feria y se convencerán de la exactitud de lo que digo (1892, p. 1)

En resumen, El Bazar Murciano pertenece a esos primeros órganos de prensa que se editaron en España por decisión de las propias empresas para establecer contactos con los públicos. De la misma época es Pompas de Jabón, house organ 
Aลก $1 .^{\circ}$

Murcia 6 de Septiembre de 1892.

NúM. $10^{\circ}$

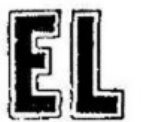

BAZAR MURCIANO

\section{ECO DEL ESTABLECIMIENTO DE SU NOMBRE}

DIREOTOR, DON RICARDO FIAZQUEZ

$$
\text { SE PUBLICARA TODAS LAS FERIAS. }
$$

SENORES: Mi propósito al publicar este periódico-prospecto, es recomendar mi cass, hacer el articulo, con la série de artículos pre. ciosos con que me han favorecido mis buenos amigos y parroquisnos y ofrecerles á Vds. nuevamente mi establecimiento. Yo no sé escribir literariamante; no entiendo de otras letras que de las letras de cambio; pero como estoy tan obligado con el público de Murcia, por lo que me favorece y me distingue; creo de mi deber corresponder á estas atenciones, haciéndolss públicas por las presentes líness, y teniendo en mi establecimiento del Bazsr Murciano, los mejores géneros del mundo, á los precios más económicos.

Venตู?n Vdes., aeñorss y señores. \& honrar mi cass en la presente féria y so convencerau , de la exsctitud de lo que digo.

Rioardo BlazQUez.

\section{BIOGRAFIA.}

\section{Ricardo Blazquez}

Este popular comerciante nació en el pueblo donde le dió á luz su buena madre, en el dia y hora que consta on ls fe de bantismo.

Desde los más tiernos meses demostró gran aficion á los cuartos... de luns, sficion que con'serva hasta el presente momento histórico.

Cuentan, que cusndo le spuntaron los primeros dientes, prefería uns pesets á los amuletos de marfil y á los pedacitos de suela que le colgaban para que se rascara las binchadas encías

Sus padres adivinsndo ls vocscion de Ricardito, le dedicaron al comercio, embalśndolo y facturándolo para Murcia á la órden del Bazar de la Puxmarina, en donde soltó pronto los andadores. El niño no corris, volaba hasta perderse de vista.

No está averiguado si eso que tiene en la pierna derecha es de algun mal paso; pero lo que está fuera de toda duda es que cojes. En esto convienen todos los autores que hemos consultado.

De noche, cuando se retirabs del mostrador y se dejaba caer en el catre, en vez de dorwir, peusabs y pensó que un dependiente podria llegar á principal, y eso de principal le gustó mucho.

Le escribió á un su tío y su tío le contestó. $\mathrm{Y}$ dicho y hecho, se estableció en la Platería con vistas á la Plaza de Jufré, donde está el kiosko.

Ricardito se dió tan buens mañs que en pocos diss llegó á donde no han llegado acreditados comerciantes.

Su caracter jovial y discreto; su amabilidad nuncs exsjerada, con las señoras; slguno que otro rasgo de explendidez (siempre con oportunidad) y su buen gusto en la eleccion de los géneros lograron que su establecimiento se viera coristantemente concurrido, y que el cajon del mostrador le diera sorpresas agradabilísimas.

Los que se encuentran en el terrible apuro de hacer un regalo de bodas; los qus tienen el compromiso de obsequiar á un smigo en el dia de su santo; el novio que tiene que dar a la novia una pruebs psipsble de su smor, y los papás que tienen que feriar $\mathbf{s}$ sus nenés de ambos sexos, necesitan recurrir al Bazar Mur. ciano y entenderse con Ricardo, qué adivina de lo que setrats y les pone delsnte de los ojos aquellos objetos que por el gusto y el precío llenan los deseos de la víctims.

La coleccion de muñecss que ha recibido para la presente féria le entra \& uno en deseos de ser niña. ¿Qué bonitas y qué barstas son! Esto de baratas lo dice Ricardo; quiza los que tengan que compralas dirß́n otra coss.

Si hemos de creer lo que dicen por ahí, en io que no tiene rival el Bazar Murcisno es en los cubiertos de metal blanco y en el ramo de perfumeria. Dicen que no boy ya señorita de buen gusto que no tengs on su tocsdor las esenciss que por poco dinero les facilita nuestro biografiado. 
de la Perfumería Gal y, según Prat Gaballí (1934), director del departamento de publicidad de la marca, surgió porque "era uno de los eslabones que hacían falta en la cadena de nuestras campañas de publicidad” (p. 68). Para Reina (2015) estas revistas de principios del siglo XX se pueden considerar un antecedente de relaciones públicas en España.

Cebrián (2012) considera que las revistas de empresa constan de cabecera fija, numeración, periodicidad regular, gratuidad y redacción propia y están orientadas a públicos internos y externos. En este punto, El Bazar Murciano cumple con todos los supuestos, si bien se dirige a públicos externos. Con respecto a la edición, Cebrián (2012) señala que las revistas de empresa no están editadas por una empresa del sector, sino por una de comunicación. También en esto El Bazar Murciano se ajusta a este requisito, ya que primero lo editó El Diario de Murcia, a partir del número 12 pasó a imprimirse en los talleres del diario La Verdad y en adelante, en la imprenta del periódico El Tiempo.

El Bazar Murciano salía todos los años por la Feria de Septiembre, la feria comercial de mayor tradición de Murcia, que se remonta a 1226, cuando Alfonso X otorga este privilegio a la ciudad (Miralles González-Conde, 2016). Puig (1996) apunta que las ferias, de origen medieval, hicieron posible "una especie de publicidad colectiva que todavía se conserva en la mayoría de nuestras ferias urbanas” (p. 94).

El señor Blázquez supo aprovechar esta ocasión festiva y multitudinaria para promocionar su bazar poniendo en práctica la famosa frase la publicidad es el arte de vender en letras de molde de John E. Kennedy (1864-1928), uno de los grandes redactores publicitarios de finales del XIX.

\section{El Bazar Murciano, contenido de marca}

En segundo lugar, los resultados del análisis de los textos a partir de la definición de branded content confirman que se trata de información de marca. Según la Asociación de Empresas Consultoras en Relaciones Públicas y Comunicación (2018) branded content es el:

...contenido producido, coproducido o auspiciado por la marca que, sin ser publicidad, transmite sus valores y posicionamiento entreteniendo, educando o formando al público al que va dirigido. La clave es que sea un contenido relevante y de interés. Que aporte valor, que conecte y que fomente la participación de los públicos generando comunidad en torno a la marca. No es, por tanto, un contenido publicitario, sino un contenido de valor que tiene detrás a una marca cuya esencia la legítima para proporcionar ese contenido. No es un marketing intrusivo, sino un contenido que es consumido libremente y proactivamente por la audiencia (p. 7). 
Si bien la importancia de las colaboraciones en los textos de El Bazar Murciano viene marcada por la categoría de los firmantes, también lo es que los poemas y los artículos publicados no desmerecen de otras obras de sus autores. Aunque el argumento parezca banal, como puede ser hablar de los objetos de un bazar, los contenidos son de valor: literarios, ingeniosos e inspirados.

Conforme con la definición, los textos de El Bazar Murciano conectan con el público de Murcia y traban una relación entre la marca y los ciudadanos que estimula el consumo. Por ejemplo, el relato costumbrista de Ricardo Sánchez Madrigal glosa el murcianismo del señor Blázquez, que por su empatía ha conseguido que los murcianos se identifiquen con el bazar. Asimismo, el poema de Pedro Jara Carrillo, Septiembre, acierta al asociar el comienzo de la esperada Feria de Septiembre con la publicación del periódico.

Por otra parte, todas las colaboraciones se ajustan a la definición en cuanto no son contenidos publicitarios, sino de valor, que legitiman a la marca para proporcionar contenido literario en cada número de la publicación. A este respecto, José Martínez Tornel en su artículo Preámbulo (ver imagen 2) confiesa: “No sé lo que tienen estas breve páginas de El Bazar Murciano que los que escribimos a diario todo el año, cuando nos dedicamos a él, quisiéramos ofrecer lo más exquisito de nuestro ingenio" (1907, p.1).

Finalmente, aunque desconocemos el número de ejemplares que se editaban, sabemos, por los testimonios de periodistas, escritores y periódicos coetáneos, que se distribuían a los periódicos locales y nacionales, instituciones culturales y sociales y amigos. Por consiguiente, inferimos que sería "consumido libremente y proactivamente por la audiencia” como indica la definición de la Asociación de Empresas Consultoras de Relaciones Públicas y Comunicación (p. 7).

En cuanto a la definición de Horrigan (2009), para quien el contenido de marca es una simbiosis de publicidad y entretenimiento que forma parte de la estrategia de la marca para distribuirse como contenidos de entretenimiento de calidad, observamos que el contenido de marca de El Bazar Murciano es una táctica de Ricardo Blázquez para promocionar sus almacenes y relacionarse con sus públicos por medio de poemas y narrativa.

Así, el artículo De los juguetes de Gabriel Miró del Bazar Murciano relaciona al dueño con la cultura, con frases como por ejemplo, "Blázquez, espíritu culto de ideales artísticos" o "juguetes blazqueños que participáis de la espiritualidad de vuestro señor excelso" (1908, pp. 2-3); y Bolarín, en el poema A mí, una muñeca, asocia el bazar con el mundo de las ilusiones, en estrofas como "reino de la maravilla, y de la ilusión palacio, es el comercio de Blázquez, llamado Bazar Murciano” (1916, p.3). Lo 


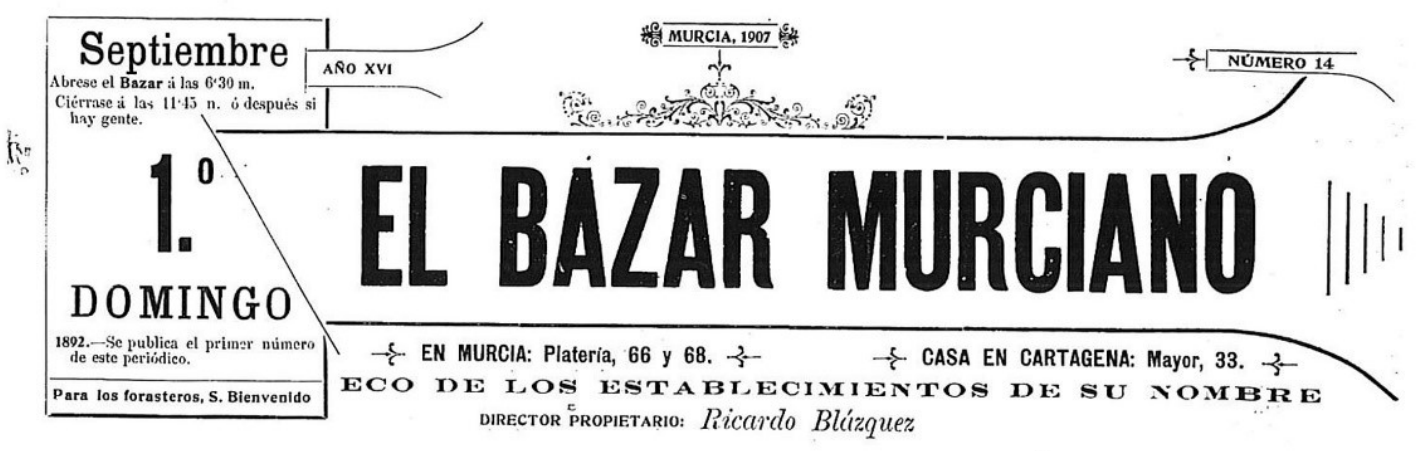

\section{Preámbulo}

$\rightarrow 9 \%-$

Empiezo à escribir este artículo pensando en Ricardo Blázquez, en el
BAZAR MURCIANO, en los escritoBAZAR MURCIANO, en los escrito-
res que han honrado con sus firmas res que han honrado con sus firmas
este periódico $y$ en el buen público

A Ricardo lo veo en mi imaginación, no ri isueño como siempre, sino con la boca cerrada, con la mirada fija en
mi y con esta pregunta muda en toda su cara: ‘¿Qué vá V. á decir?. . FI Su cara: ‘QQué vá V. á decir??, tablecimiento, creo que me interrogan del mismo modo. Mis compañeros de redacción, los insignes colaboradores, no me preguntan nada; soy yo el que me digo, qué puedo yo poner aqui que sea digno de preceder á sus ingeniosos escritos, á la autoridad de su nombre. U'ltiinamente el buen público, que favorece al BAZAR y forma la escogida $y$ amable clientela de Ricardo, no me preocupa

Pues bien, á todos les digo alborozado que hemos entrado en el año deriódico neriódco, y que parece que ni por él, criben, ni por el público, han pasado años. Somos lo que queda enhiesto de nuestra féria, lo que no decae, el festejo culto, poético, murciano por excelencia; certámen sin premios, y Juegos Florales con una reina, este
a'io, como la soberana del Arte María a'io, como
Guerrero.

No sé lo que tienen estas breves páginas del BAZAR MURCIANO, que aun los que escribimos á diario to to el año, cuando no3 dedicamos á sito de nuestro orecerle tomás exquia santificar las fiesto: Y por eso, comb en ligera y fácil prosa, en graciosos o sentidoz versos, se encuentra el lector, la murcianeria andante y cantante, la trova guitarresca, el himno á la Torre. la pirra $7 d a$ resiqueteadora, la malagueña melancólica de la madrugada, el rumor soñolento y pavoroso de los conjuros, el voluptuoso perfume de ciones místicas del inmortal génio de ciones mistillo.
Salzill

Esto, y leer estas páginas, es como venir de la Sierra de la Fuensanta her he arrodila delallo de la gen, haber cogido tomilo, romero y 供 tallos de olivo, haber lenado el anfora rumoroso que nace bajo aquelios pinos, y beber entre suaves y sano aromas el agua incomparable, castálica, de la Fuente de la Luz. Yo la bebo, á la salud de todos,en la jarra murcia$\mathrm{na}$, que la trasmana fresca $\mathrm{y}$ rebosante, colgada en la esquina de la barra-

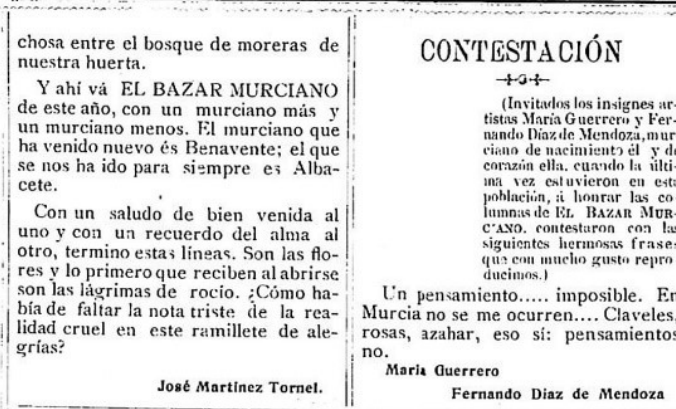

\section{DESPEDIDA}

\section{$\rightarrow$ w-}

Del lujoso escaparate al rincón donde dormitan los munecos invendibles ha bajado el buen Pierrot. Por lo añejos desagradan su inocencia y su ropaje. Ya Pierrot pasó de moda y envejece como yo.

Sus pueriles travesuras á los niños no interesan, que en los años que corremos es la infancia muy precoz. Como nadie escuchar quiere su; canciones á la luna solo á mi me las recita, ;pobre loco sonador!

Es muy triste, pero es justo; nuevos tiempos, nuevas cosas: todo sufre los rigores del Progreso: ¿cómo no? A la estrofa legendaria sucedió la modernista y el minúsculo automóvil al caballo de car:ón.

Muy bien hecho, señor Blázquez, si retira de la venta los muñecos anticuado;; pero diga por favor: ¿por qué quiere que otros viejos que pasamos ya de mola abusemos, importuno3, de la pública atención?

Sus caprichos como leyes acaté; pero al encanto de otras voces juveniles apagar debo mi voz.

Acabóse la comedia: perdonad sú muchas faltas.

Ya Pierrot por señas dice que me espera en su rincón.

Santa Pola 19 Agosto 19\%\%

RICARDO GIL

\section{UNA Y NO MÁS $\rightarrow \infty-$ \\ Tiene por tener Marian} de todo como en botica, bolsa pobre, novia rica $y$ un tío que es arcediano.

La novia no admite loa, pues es más fea que Picio $y$ no tiene desperdicio para mascarón de proa.

Como â estatura menguada une el pesar kilos cien, afirman cuantos la ven afirman cuantos la ven
que es una fea apaisada.

Sin ser para nadie arcano que tiene una calva tal, que la palma de la mano.

Mas, como tiene un millón, el novio, por bien tan pingüe, la lama, y no es lapsus lingine, Fs rico el tio también y, por presumir de mozo, le achaque más de un belén. Bueno, pues siendo llegada cuyo nombre es el del cura, y el nombre de la adorada; Fara obsequiarles puntual, por ser cosa de cajón, á él de respeto en señal

á un Bazar corrió Mariano $y$, después de revolverio sin darle paz á la mano

dió término á sus fatigas comprándole al sacerdote y á ella unas preciosas ligas.
.

Pagó y al dueño rogó que mandara con premur su adorada y al cura lo que á una y á otro comprọ́; dándolo de cada cual, del buen éxito en auxilio; las señas del domicilio, como era lo natural.

Mas joh doloz! a las pocas horas de enviar lo: regalos, en lugar de gracias, palos
recibió á tontas y á locas.

Fl cura en ira montó y desheredó á Mariano; y á paseo le mandó.

Pues por su maldita estrella, armando el Bazar un lío, y el Petróleo Gal á ella.

Por eso á Mariano agobia la pena $y$ aún hoy murmura: - iRegalar ligas a un cura! ¡Mandar petróleo á una novia!Desde aquel lance Mariano, para otro lio evitar, cuando quiere regalar
acude al BAZAR MURCIANO.

Porque la fama pregona que su dueño, hombre muy largo, es para cualquier encargo Carlos Cano

\section{MIŚ JUGUE'I'ES} $\rightarrow$ - * -

Sr. D. Ricardo Blázquez: Simpático señor $y$ amigo: En vísperas de pisar el estribo del tren, es de razón como una Giraldaros y el colo, recibo la amable carta de V. pidiéndome el saludo de siempre á bellísimos juguetes del Bazar Murcio"17, al cual, por una excepción jama vista en España, ni creo que en el mundo, vienen cantando anualmente los espiritus mas altos de la literatura gular? iSe concibe que cosa más sinmas gloriosas, las plumas de de plutoda una época, se pongan cada año á enaltecer un rico comercio murciano? ¿Por qué ese caso rarísimo? ¿Por qué lés da la real gana á esos : hombres que componen el Estado Mayo de las Letras, de ensalzar los objetos de un rada Murcia, y que se denomina $\mathrm{Ba}$ la fantasia los bazares prestan más de hay originalidades, telas Ilamativas, cacharros exóticos, objetos prendentes, elaboraciones del cosmopolitismo? $\mathrm{Si}$, se prestan más á la'fantasía los bazares de universal re+ nombre para pintar con la palabra

Imagen 2. $\mathbf{N}^{\circ} 14$ de El Bazar Murciano (1907)

Fuente: Hemeroteca digital Archivo Municipal de Murcia. 
mismo hace Martínez Tornel en su citado artículo Preámbulo cuando dice "empiezo a escribir este artículo pensando en Ricardo Blázquez, en el Bazar Murciano, en los escritores que han honrado con sus firmas este periódico y en el buen público que nos ha de leer a todos" (1907, p. 1). En este último, ciertamente habla del periódico, de los colaboradores, el comercio, el propietario y el público como una unidad que ha funcionado en Murcia porque ha conseguido integrarse en la ciudad.

Los resultados del análisis del contenido de marca a partir de los tres ítems propuestos demuestran, primero, que la marca es el centro del relato en las seis colaboraciones, es decir, que El Bazar Murciano periódico, el establecimiento del mismo nombre y Ricardo Blázquez aparecen citados en todos los textos: cuatro veces en el poema de Jara Carrillo, tres en el artículo de Gabriel Miró, trece en el de Martínez Tornel, ocho en el de Bolarín, cuatro en el de Ortega Munilla y siete en el de Sánchez Madrigal.

En segundo lugar, se comprueba que el eje narrativo está asociado a la marca y forma parte del storytelling. Por ejemplo, el texto narrativo de Gabriel Miró es, por un lado, un elogio al dueño, que hace felices a los más pequeños porque en el fondo él es un niño grande y, por otro, una descripción precisa de los juguetes, que desfilan por el artículo.

Con respecto a la colaboración de José Ortega Munilla El bazar es un periódico (ver imagen 3), se trata de un relato muy favorable sobre el propietario del bazar, a quien felicita por su habilidad para la venta y por la publicación que dirige. En el artículo de Ricardo Sánchez Madrigal, la historia gira en torno al dueño, quien no duda en calificar su establecimiento de murciano.

La identificación con el territorio es una constante en los escritores locales de la época impregnados del movimiento literario regionalista, entonces de moda. Así, muchos de los artículos describen la singularidad de la urbe: las calles, el paisaje, las costumbres, la vida intelectual y provinciana, y ponen de relieve la condición de ciudad comercial que ostentaba Murcia.

En tercer lugar, podemos ver que la notoriedad del contenido de marca se percibe en las seis colaboraciones de manera nítida; por ejemplo, en la poesía de Pedro Jara Carrillo el lector advierte enseguida que entre tanto barroquismo de palabras el autor se está refiriendo al periódico El Bazar Murciano, del mismo modo que en el poema de Andrés Bolarín dedicado a los juguetes es evidente que todas esas maravillas se venden en el comercio del señor Blázquez.

Al lector del artículo de José Martínez Tornel no le cabe duda de que el comentario del decimocuarto aniversario del periódico, al que muchos escritores han honrado con sus firmas, no es otro que el periódico objeto de estudio. 


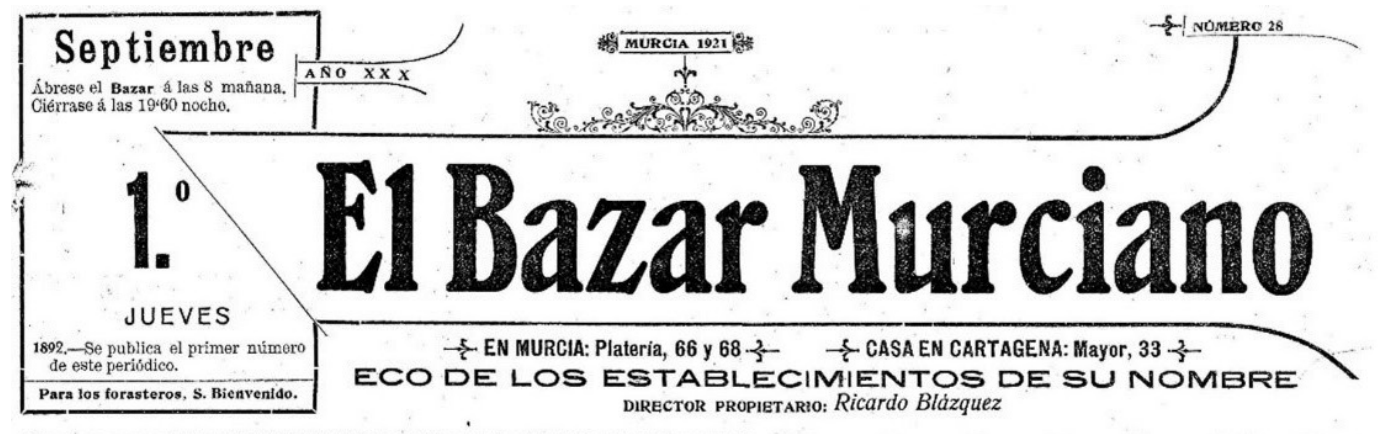

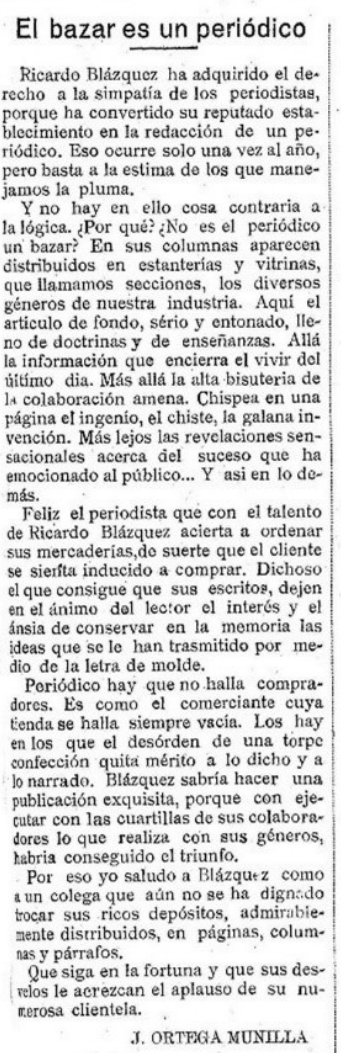

Incongruencias veraniegas

$$
\begin{aligned}
& \text { Con los caloros pasan } \\
& \text { horas terribles } \\
& \text { de incombustibles. } \\
& \begin{array}{l}
\text { no no hay Bazar ningnno } \\
\text { como el Mexriaso! }
\end{array} \\
& \text { fay muckos saimales } \\
& \text { que en el estío } \\
& \text { no tienen frfo. } \\
& \text { Y a firmas Pozas } \\
& \text { van buevas mozas. } \\
& \text { En verano tenemos } \\
& \begin{array}{l}
\text { rioos melones, } \\
\text { se crían a fuerza }
\end{array} \\
& \begin{array}{l}
\text { de insolaciones. } \\
\text { Blázquez en tant }
\end{array} \\
& \text { ade de Gal perfumes } \\
& \begin{array}{l}
\text { Hay quien sudando el quilo } \\
\text { vá por la Corte, }
\end{array}
\end{aligned}
$$

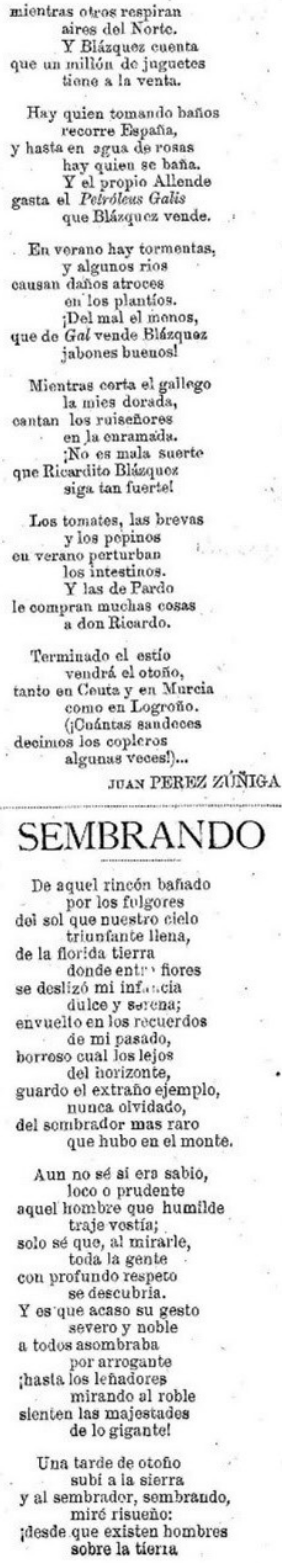

mientras otros respiran
aires del Nortc. Y Blázquez cuenta que un milíón de juguetes
tiene $\mathrm{a} ! \mathrm{a}$ venta.

Hay quien tomsndo baños recorre Eispafía,
hasta en ogua de ros

hasta en guas do rosas
hay quen ge baña. Y el propio Allende que Bláxqucz vende.

En verano hay tormentas, y algunos riog
danos atroces eni los plantios. iDel mal el manos, jabones buenos!

Mientras corta el galleg la mies dorads, en la enramada. ;No es mals suerte que Ricardito Blíeque tan fuerte?

Los tomates, las brevas $y$ los pepinos los intestinos.
$\mathrm{Y}$ las de Pardo a don Riourdo.
a compran muchas cosas

Terminado el estio tanto en Couta y en Mrarei como en Logroũo. (iCuántas sandeo eoimos los copleros
algunss veces?

JOAY PERTY ZINNTGA

\section{SEMBRANDO}

De aquel rineón bafiado por los fulgores doi sol que nuentro cielo de la florida tierra

de la flor:da terra
donde ent.' fiores

se deslizo mi infa t.cia

dulce y sotena;
envueito en los recueráos borroso cual pasado,

borroso cual los lejo
del horizonte,

guardo el extraño ejemplo, nunca olvidado,
del sembrador mas raro que hubo en el monte.

un no sé ai ers sabio,

1000 o prudente
nuel hombre que humild

aquel hombere que humide
traje vostia;

solo sé que, al mírarle, toda la gente

con profundo respec
se descubria.

$\mathrm{Y}$ es que acaso su gesto

a todos asombraba

ihasta los leñadores

mirando al roble de lo gigante!

Una tarde de otońo al sembrador, sembraudo, mirć risueño:
;đesde que existen hombres
sobre la tierna DIREctor PROPIETARı: Ricardo Blázquez

$$
\begin{gathered}
\text { sermbrando amores } \\
\text { con la vista y el alma } \\
\text { siempre en la altura. } \\
\text { Dijo al loco, } y \text { con noble } \\
\text { me 'ancolía } \\
\text { por ias breñas del monte } \\
\text { siguío trepando, } \\
\text { y, al perderse en las sombras, } \\
\text { aun repetia: } \\
\text {-iElay que vivir sembrando! } \\
\text { jSiempre sembrandol }
\end{gathered}
$$
M. R. BLANOO-BELMONTE

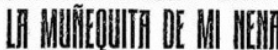

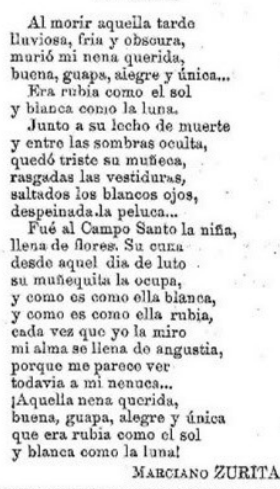

En la puerta del Bazar

PSTCOLOGUA DIT. SALCDO MREMKNINO Si os fijais en las formas mimicas del sa so a trea: la sonriss, un pueder redcoir miento de cabeza o un gesto despeetivo que pone de reliove ia mandibula inferios
Por la sonrisa, la gracia de la mujer no oncanta y embriaga o su desgraoia nos desmejor de 8n alma $8, c 0 m 0$ su alma, a sonti es fria o es.... gris.

tia movisto reveroncioso de dobla patricio. Ii cuello femenino delicado plástico, se pliega con el grácil encanto de yello aristocratico de los cisnes. Y queda el gesto. Kl gesto en sí es ad rosto naior considerable. pismo de actividad $y$ de aho:ro, or gesto ro prosenta la síntecis. Eyo gesto fomonin que para saludar ochis alrás violentamezis grotasco, «s anípático: nos habls de sufer ruismo, de osteriliàad, de bas blens, de oosas esoneia:mente antifemeninas. Aparto su descortesia despectiva, ese gesto tiente un doloroso valor sinbolico; in furción más noble de la mandíbula os la masticacion $y$ habremos de coneluir oue por mucho quo divinicemos a la inujer, no podremos llogar Labla la id dea do que Hegel zostenía que en el rostro humaso hay una parte noble: ia frente; $y$ otra inno. ble; la mandỉbula; la boca es ambigua; la nariz puede ser un signo ovidente de supe-

Imagen 3. № 28 de El Bazar Murciano (1921)

Fuente: Hemeroteca digital Archivo Municipal de Murcia 
Respecto de la naturaleza de los contenidos, todos los artículos son literarios, un género en auge en aquel momento en los periódicos, como pone de relieve el elevado número de escritores y poetas que escribían en la prensa y concurrían a los Juegos Florales, concursos poéticos y tertulias literarias que proliferaban en distintas ciudades. Como han destacado Seoane y Dolores Sáiz (1998),

el periodismo español [del primer tercio del sigloXX] —deficiente por el lado de la información, sobre todo si se lo compara con el del ámbito anglosajón o germánico - brilla a extraordinaria altura en el aspecto intelectual y literario, porque se nutre en gran medida de las plumas de escritores e intelectuales, en una época excepcional de la cultura española (p. 62).

Con respecto a la autoría, de la lectura de El Bazar Murciano se deduce que se trata de una revista cultural de calidad, en la que colaboraron los poetas, escritores, periodistas y dibujantes del momento: el director de El Diario de Murcia y maestro de periodistas Martínez Tornel, el director de El Liberal y poeta Jara Carrillo, el director de El Tiempo Nicolás Ortega, otros periodistas locales como Mariano Perní y Bautista Montserrat, así como poetas - por ejemplo, Ricardo Gil, Frutos Baeza, Vicente Medina, José Selgas, Vicente Llovera, Francisco Flores, Carlos Cano, Frutos Baeza...-, pintores, como Gil de Vicario, y grandes firmas nacionales, entre las que se encuentran el poeta Salvador Rueda, los escritores Gabriel Miró, Azorín, Jacinto Benavente, José Echegaray, y en los años veinte José Ortega Munilla, Torcuato Luca de Tena y Wenceslao Fernández Flórez.

Como se ha mencionado al principio de este trabajo, Crespo (1984) ha contabilizado 135 colaboradores y un total de 819 colaboraciones: 540 en verso y 279 en prosa.

Y es que desde finales del siglo XIX las marcas solían acudir a prestigiosos dibujantes y escritores para promocionarse, aprovechando su prestigio y popularidad entre los lectores de la burguesía acomodada. En España existen varios casos: la revista quincenal El Siglo, desde 1883 órgano de los almacenes barceloneses del mismo nombre, tuvo excelentes colaboradores, que representan lo más granado del movimiento artístico y literario del Modernismo, con redactores que habían trabajado para la revista Vida Nueva y reputados dibujantes como Pellicer y Apeles Mestres. Igualmente, desde 1917 la perfumería Floralia venía publicando en las mejores revistas gráficas una página de información de marca realizada por magníficos dibujantes y caricaturistas en un periodo de esplendor de la ilustración gráfica en España (Arroyo Cabello, 2018). 


\section{CONCLUSIONES}

La publicidad técnica en España se gesta en el primer tercio del siglo XX ligada a la transformación económica y social del país. En este proceso sobresale la figura de Pedro Prat Gaballí, considerado el padre de la publicidad moderna española, cuyo ingente legado le sitúa a la altura de otros países. No obstante, cabe destacar la función de los empresarios que, sin bagaje teórico, se adelantaron a su tiempo utilizando formas de comunicación comercial todavía innominadas.

Este es el caso de Ricardo Bázquez, fundador y director del periódico El Bazar Murciano, órgano de unos grandes almacenes y uno de los primeros house organs que se editaron en España. Autores de la época, como Pedro Prat Gaballí, Rafael Bori y José Gardó, se refieren al periódico privado en términos que se reconocen en El Bazar Murciano.

Se trata de una publicación anual, cuyo primer número salió el 1 de septiembre de 1892 coincidiendo con la Feria de Septiembre, y el último en 1929, y por su calidad literaria constituye un referente en la historia del periodismo local.

Además, este periódico de empresa es pionero en contenido de marca, un instrumento para fidelizar a sus clientes e inducir al consumo con contenido de valor; un híbrido de publicidad y entretenimiento, como diría David Horrigan (2009), que responde a la estrategia global de la marca.

Su particularidad reside en los contenidos poéticos y narrativos, en auge por entonces en la prensa, y en el prestigio de las firmas.

Sus 38 ejemplares contienen más de ochocientas colaboraciones literarias de los mejores escritores y poetas de la época, tanto de la esfera local como nacional, que se ciñen a las peculiaridades del contenido de marca.

En suma, El Bazar Murciano forma parte de la historia del periodismo local y, a partir de ahora, de la historia de la publicidad, y ante la eventualidad de otros hallazgos consideramos conveniente que se prosiga esta línea de investigación, en la que se recupera la memoria de la profesión publicitaria.

\section{REFERENCIAS}

Alonso, L. E. \& Conde, F. (1994). Historia del consumo en España. Una aproximación a sus orígenes y primer desarrollo (History of consumption in Spain. An approach to its origins and development). Madrid, Spain: Debate.

Arribas Macho, J. M. (1994). Antecedentes de la sociedad de consumo en España: de la Dictadura de Primo de Rivera a la II República (Background of the consumer society in Spain: from the Dictatorship of Primo de Rivera to the Second Republic). Política $y$ Sociedad, (16), 149-168. Retrieved from https://revistas.ucm.es/index.php/POSO/article/view/ POSO9494120149A/30294 
Arroyo Cabello, M. (1994). El periodismo cultural en Murcia (1900-1932) (Cultural journalism in Murcia (1900-1932)). Murcia, Spain: Fundación Instituto de la Comunicación de Murcia.

Arroyo Cabello, M. (1997). Grandes hitos del periodismo murciano (Great milestones of Murcian journalism). In M. Núñez Díaz-Balart, A. Martínez de las Heras, \& R. Cal Martínez, (Eds.), José Altabella. Libro homenaje (José Altabella. Tribute book) (pp.613-625). Madrid, Spain: Facultad de Ciencias de la Información.

Arroyo Cabello, M. (2018). Perfumería Floralia: un caso de contenido de marca a principios del siglo XX (Parfum shop Floralia: A case of branded content at the beginning of the twentieth century). Pensar la Publicidad. Revista Internacional de Investigaciones Publicitarias, 12, 91-108. Retrieved from http://hdl.handle.net/10952/3496

Apuntes sobre la publicidad y la perfumería en España (Notes on advertising and perfumery in Spain). (1950). Arte Comercial, Revista técnica de publicidad y organización, 24-27.

Asociación de Empresas Consultoras en Relaciones Públicas y Comunicación. (2018). Guía de storytelling y branded content (Guide to storytelling and branded content) (PDF file). Retrieved from http://adecec.com/wp-content/uploads/2018/09/la-guia-de-storytellingy-branded-content-de-adecec.pdf

Ayuso, M. D. \& García, T. (2011). Costumbrismo y folklore en Murcia en el periodo de la Restauración (1875-1902) (Costumbrismo and folklore in Murcia in the period of the Restoration (1875-1902)). Murgetana, (125), 159-188. Retrieved from http://www.regmurcia.com/docs/murgetana/N125/N125_007.pdf

Ballester Nicolás, J. (1971). Amanecer de la prensa periódica en Murcia (Dawn of the periodic press in Murcia). Murcia, Spain: Academia Alfonso X el Sabio.

Barceló Jiménez, J. (1982). Los toros, el periodismo y la literatura en Murcia (Bulls, journalism and literature in Murcia). Murcia, Spain: Academia Alfonso X el Sabio.

Blázquez, R. (1892, September 6). Señores (Ladies and gentleman). El Bazar Murciano.

Bori, R. \& Gardó, J. (1928). Manual Práctico de Publicidad (II) (Advertising handbook (II)). Barcelona, Spain: Editorial Cultura.

Bravo, J. (1978). J. Walter Thompson España. De 1927 a 1936 (J. Walter Thompson Spain. From 1927 to 1936). Madrid, Spain: J.W.T.

Capriotti, P. (2007). La responsabilidad social corporativa de las empresas españolas en los Medios de Comunicación (The Corporate Social Responsability of Spanish Companies in the Mass Media). ZER - Revista de Estudios de Comunicación, 12(23), 61-74. Retrieved from https://www.ehu.eus/ojs/index.php/Zer/article/view/3642

Cebrián, M. (2012). Periodismo empresariale institucional (Business and institutional journalism). Sevilla, Spain: Comunicación Social.

Crespo, A. (1984). Un periódico curioso: El Bazar Murciano (1892-1929) (A curious newspaper: El Bazar Murciano (1892-1929)). Murgetana, (66), 17-32. Retrieved from http://www.regmurcia.com/docs/murgetana/N066/N066_002.pdf

Crespo, A. (2000). Historia de la prensa periódica en la ciudad de Murcia (History of the press in the city of Murcia). Murcia, Spain: Real Academia Alfonso X el Sabio.

Checa Godoy, A. (2007). Historia de la Publicidad (Advertising History). La Coruña, Spain: Netbiblio. 
Díez de Revenga, F. J. \& De Paco, M. (1989). Historia de la literatura murciana (History of Murcian literatura). Murcia, Spain: Academia Alfonso X el Sabio. Retrieved from http://www.cervantesvirtual.com/obra/historia-de-la-literatura-murciana-923264/

Eguizábal Maza, R. (1998). Historia de la Publicidad (Advertising History). Madrid, Spain: Eresma\&Celeste.

Eguizábal Maza, R. (2006). Del consumo de élite al consumo de masas (From elite consumption to mass consumption). In M. C. Alvarado López \& M. I. Martín Requero (Coords.), Publicidad y cultura: la publicidad como homologador cultural (Advertising and culture: advertising as a cultural homologator) (pp. 62-93). Sevilla, Spain: Comunicación Social Ediciones y Publicaciones.

El Liberal de Murcia. (1927, September, 4th), p. 1.

Faciabén, P. (2003). Los grandes almacenes en Barcelona (Stores in Barcelona). Scripta Nova. Revista Electrónica de Geografía y Ciencias Sociales, 7(140), 1-28. Retrieved from http://www.ub.edu/geocrit/sn/sn-140.htm

Fernández Poyatos, M. D. (2010). Las primeras agencias españolas de publicidad: 1912-1934 (The first Spanish advertising agencies: 1912-1934). Questiones Publicitarias, (15), 52-71. https://doi.org/10.5565/rev/qp.83

Ferrández García, J. I. (2017). Comercios antiguos de Cartagena y su publicidad (Old shops of Cartagena and their advertising). Cartagena, Spain: Ayuntamiento de Cartagena.

Fusi, J. P. (2007). La cultura (Culture). In S. Juliá, J. L. García Delgado, J. C. Jiménez, \& J. P. Fusi (Eds.), La España del siglo XX (Twentieth Century Spain) (pp.531-738). Madrid, Spain: Marcial Pons.

Folguera, P. (1987). Vida cotidiana en Madrid. Primer tercio del siglo a través de fuentes orales (Daily life in Madrid. First third of the century through oral sources). Madrid, Spain: Comunidad de Madrid.

García Delgado, J. L. (2002). La modernización económica en la España de Alfonso XIII (The economic modernization in the Spain of Alfonso XIII). Madrid, Spain: Espasa.

Hopkins, C. (1923). Scientific advertising. New York, NY: Lord \& Thomas.

Horrigan, D. (2009). Branded content: a new model for driving Tourism via film and branding strategies. Tourismos: an international multidisciplinary refereed journal of tourism, 4(3), 51-65. Retrieved from http://www.chios.aegean.gr/tourism/vol4iss3.htm

Martínez Tornel, J. (1906). Hacer el artículo (To create the article). El Bazar Murciano.

Martínez Tornel, J. (1907). Preámbulo (Foreword). El Bazar Murciano.

Miralles González-Conde, M. (2016). El cartel de fiestas en Murcia (1960-2015) (The party poster in Murcia (1960-2015)). (Doctoral dissertation). Retrieved from http://repositorio.ucam.edu/handle/10952/1615

Miró, G. (1908). De los juguetes (About the toys). El Bazar Murciano.

Montero, M. (2011). La publicidad española en el primer ensayo de sociedad de consumo (1920-1936). Un enfoque histórico (Spanish advertising in the first consumer society trial (1920-1936). A historical approach). Sphera Pública, (11), 351-368. Retrieved from http://hdl.handle.net/10171/19195 
Moreno Requena, M. (2007). Gabriel Miró y Murcia (Gabriel Miró and Murcia). Murgetana, (117), 137-163. Retrieved from http://www.regmurcia.com/docs/murgetana/N117/N117_009.pdf

Pérez Ruiz, M. A. (2001). La publicidad en España. Anunciantes, agencias y medios 1850-1950 (Advertising in Spain. Advertisers, agencies and media 1850-1950). Madrid, Spain: Fragua.

Prat Gaballí, P. (1917). Publicidad científica (Scientific advertising). Barcelona, Spain: Imprenta de Henrich Cia.

Prat Gaballí, P. (1934). Publicidad racional (Rational advertising). Barcelona, Spain: Labor.

Prat Gaballí, P. (1957). Publicidad combativa (Combative advertising). Barcelona, Spain: Labor.

Puig, J. (1996). 5000 años de Historia del Comercio y la Publicidad. La aventura de la comunicación publicitara y comercial (5000 years of History of Commerce and Advertising. The adventure of advertising and commercial communication). Barcelona, Spain: RosalJai.

Quintas Froufe, E. (2011). El legado del hombre que se tomó la publicidad en serio: Pedro Prat Gaballí. Aproximación a sus contribuciones teóricas y profesionales (The legacy of the man who took advertising seriously: Pedro Prat Gaballí. A look at his theoretical and professional contributions). Área Abierta, 30(3), 1-18. https://doi.org/10.5209/rev_ARAB.2011.n30.37838

Reina, J. (2015). Las revistas de empresa en España: algunos ejemplos de house organ desde principios del siglo XX (House Organ in Spain: some examples from the early twentieth century). Revista Internacional de Relaciones Publicas, 5(10), 85-104. Retrieved from http://revistarelacionespublicas.uma.es/index.php/revrrpp/article/view/338

Rodríguez Llopis, M. (1998). Historia de la Región de Murcia (History of the Region of Murcia). Murcia, Spain: Editora Regional.

Rubio Román, E. (2012, January 3). El Bazar Murciano. La Opinión de Murcia, p.6.

Rudmani, G. (1888). Royal Baker Pastry Cook. New York, NY: Royal Baking Powder Company.

Seoane, M. C. \& Sáiz, M. D. (1998). Historia del periodismo en España, 3, El Siglo XX: 1898-1936 (History of journalism in Spain, 3, The twentieth century: 1898-1936). Madrid, Spain: Alianza.

Valcárcel, C. (1902). El Bazar Murciano.

\section{SOBRE LA AUTORA}

MARÍA ARROYo CABELLO, doctora en Ciencias de la Información. Profesor Contratado Doctor en la Universidad Católica de Murcia (España), con un sexenio de investigación reconocido. Sus líneas de investigación son la historia del Periodismo, la historia de la Publicidad y de la Comunicación local. Es autora de dos libros y de más de una veintena de artículos científicos sobre la influencia de la comunicación en la sociedad, la cultura y la política.

iD http://orcid.org/0000-0001-9896-9263 